\title{
柔性电致变色器件研究进展
}

\author{
方华靖 ${ }^{1}$, 赵泽天 ${ }^{1}$, 武文婷 ${ }^{1}$, 汪 宏 $^{2}$
}

(1. 西安交通大学 材料科学与工程学院, 西安 $710049 ; 2$. 南方科技大学 材料科学与工程系, 深圳 518055)

摘 要: 电致变色材料是一类重要的光电功能材料, 可以随周期性调整的电压改变颜色。这种可控的光学吸收率和 透过率的调制在智能窗户、电致变色显示和防眩光后视镜等应用场合大显身手。近年来电致变色技术发展迅速, 但 当前的研究大多集中在传统刚性电致变色器件, 通常以氧化铟锡(ITO)等导电玻璃为基底。这些刚性变色器件存在 厚度大、共型性差、机械强度低、成本高等不可忽视的问题，阻碍了电致变色技术及其商业化的发展。伴随着开发 可穿戴设备和电子皮肤等其他未来技术的热潮, 柔性电致变色器件因其可折叠性、可穿戴性甚至可嵌入性而备受关 注, 已跻身成为电致变色领域的研究热点。本综述从制备柔性电致变色器件的材料出发, 系统地概述了无机、有机、 无机/有机复合及其他新型柔性电致变色器件最新进展和趋势, 着重介绍了可拉伸电致变色器件的国内外研究进 展。同时讨论了现阶段柔性电致变色器件在性能提升和实际应用等方面遇到的挑战, 以及国内外研究者采取的应对 措施。最后明确了柔性电致变色器件制备与提升性能的关键，并对未来的发展趋势做出展望。

关 键 词: 电致变色器件; 柔性器件; 可拉伸; 智能窗户; 制备; 综述

中图分类号: TQ174 文献标识码: A

\section{Progress in Flexible Electrochromic Devices}

\author{
FANG Huajing ${ }^{1}$, ZHAO Zetian ${ }^{1}$, WU Wenting ${ }^{1}$, WANG Hong ${ }^{2}$
}

(1. School of Material Science and Engineering, Xi'an Jiaotong University, Xi'an 710049, China; 2. Department of Materials Science and Engineering, Southern University of Science and Technology, Shenzhen 518055, China)

\begin{abstract}
Electrochromic materials with ability of changing color in response to periodically adjusted bias are an important class of optoelectric functional materials. The controllable modulation of light absorption and transmission can make a great contribution in applications such as smart windows, electrochromic displays and antiglare rear-view mirrors. In recent years, electrochromic technology has developed rapidly. However, the research so far mainly focuses on the traditional rigid electrochromic devices (ECD), mostly based on transparent conductive glass such as indium tin oxide (ITO) glass. The rigid electrochromic devices have some noticeable problems such as large thickness, poor conformability, low mechanical strength, high cost, etc., which hinder their further development of electrochromic technology and their forward commercialization. With the upsurge of developing flexible devices that can be used in wearable devices and e-skin, flexible electrochromic devices (FECD) have attracted extensive attention due to their possibility of foldability, wearability and even embeddability, and have become a research hotspot in the
\end{abstract}

收稿日期: 2020-02-16; 收到修改稿日期：2020-05-05; 网络出版日期：2020-08-01

基金项目: 国家自然科学基金(61631166004, 51902250)

National Natural Science Foundation of China (61631166004, 51902250)

作者简介: 方华靖(1989-), 男, 副教授. E-mail: fanghj@xjtu.edu.cn

FANG Huajing(1989-), male, associate professor. E-mail: fanghj@xjtu.edu.cn

通信作者：汪 宏，教授.E-mail: wangh6@sustech.edu.cn

WANG Hong, professor. E-mail: wangh6@sustech.edu.cn 
electrochromic field. Starting from the materials for preparing FECD, this review systematically summarizes the recent progress and trend of flexible electrochromic devices based on inorganic, organic, inorganic/organic composite and other new materials. The review also focuses on the research progress of up to date stretchable electrochromic devices. At the same time, challenges in performance improvement and practical application of flexible electrochromic devices at the present stage as well as the corresponding measures taken in the literatures are discussed. Finally, the key to the preparation and performance improvement of flexible electrochromic devices is defined, and the future development trend is prospected.

Key words: electrochromic devices; flexible devices; stretchable; smart window; preparation; review

电致变色技术从 19 世纪 60 年代发展至今, 在 智能窗户、防眩目后视镜、显示器等领域的应用中 取得了广泛的成功 ${ }^{[1-2]}$ 。近几十年来, 我国电致变色 技术历经从无到有的过程，在理论研究和应用探索 等多个方面都获得了重要的进展 ${ }^{[3-4]}$ 。当前大多数电 致变色器件(Electrochromic device, ECD)通常建立 在玻璃等刚性基底上, 存在厚度大、共型性差、机 械强度低、成本高和运输困难等不可忽视的问题。 与此同时, 随着柔性和可穿戴设备在移动出行、生 物医学、消费电子产品等多个应用领域的不断出现, 人们对开发廉价节能、便携灵活且能适应各种应用 场景的电子设备的需求更加强烈, 迫切需要下一代 电子产品在柔性、可折叠性、可穿戴性甚至可植入 性方面成为可能 ${ }^{[5]}$ 。柔性电致变色器件应运而生, 不 仅成本更低, 还可以在复杂的曲面进行贴装 ${ }^{[6]}$, 引 起了相关领域的国内外科研工作者们的广泛关注。

柔性电致变色器件指在高分子塑料等柔性基底 上制备的，在长周期的连续机械变形下仍保持高性 能的, 光学性质可通过施加电场而可逆改变的电子 器件。赋予电致变色器件以柔性和可拉伸性等机械 特性, 可以实现自适应伪装、仿生、可穿戴显示器 和变色服装等多种新型高端应用 ${ }^{[7]}$ 。

柔性电致变色器件通常由柔性基底(Soft substrate)、透明导电电极(Transparent conductive electrode, TCE)、电致变色层(Electrochromic layer, EC layer)、离子存储层(Ion storage layer)和电解质层 (Electrolyte layer)组成。按照电致变色材料类别可分 为无机、有机、无机/有机复合及其他柔性电致变色 器件, 常基于着色效率、光学调制范围、切换速度、 寿命和循环稳定性来评估其性能。本文综述了无机、 有机、无机/有机复合等柔性电致变色器件的国内外 研究进展, 系统介绍了柔性器件中不同电致变色材 料的优缺点, 讨论了柔性电致变色器件在性能提升 和实际使用中面临的挑战, 总结并展望了柔性电致 变色器件的未来发展趋势。

\section{1 无机柔性电致变色器件}

无机电致变色材料是最早进行研究的电致变色 材料, 具有化学稳定性高、抗辐射性能好、易实现 整个器件的全固化封装等优点 ${ }^{[8]}$ 。无机电致变色材 料主要包括金属氧化物与普鲁士蓝等, 施加电压后 因其中过渡金属离子价态和浓度不同而显现出不同 的颜色。在无机柔性电致变色器件的制备中, 常遇 到循环次数较多后材料和基底脱离的界面故障使性 能降低、电极稳定性不强、电解质漏液等问题, 因 此在提高薄膜与柔性基底的附着力、保护电极、实 现全固态 ECD 封装等方面有待探索。

\section{1 金属氧化物}

此类化合物种类繁多，包括氧化态无色而还原 态着色的阴极电致变色材料(如 $\mathrm{WO}_{3} 、 \mathrm{MoO}_{3} 、 \mathrm{TiO}_{2}$ 等) 以及还原态无色而氧化态着色的阳极电致变色 材料(如 $\mathrm{NiO} 、 \mathrm{MnO}_{2} 、 \mathrm{~V}_{2} \mathrm{O}_{5}$ 等), 金属氧化物在柔性 基底上的沉积方法有电子束蒸镀、喷涂法、射频磁 控溅射等, 可以较紧密地与柔性基底结合, 实现 ECD 的机械稳定性。

\subsection{1 氧化铇}

氧化铇具有非晶态响应速度快、多晶态对红外 光调制明显的优点, 研究历史最为悠久。2015 年, 何金等 ${ }^{[9]}$ 结合稀酸处理和机械压印方法, 在柔性聚 对苯二甲酸乙二酯 (PET) 基底上构建银纳米线 $(\mathrm{Ag} \mathrm{NWs}) /$ 聚乙烯醇 $(\mathrm{PVA})$ 复合透明电极, 引入 $\mathrm{WO}_{3}$ 基柔性电致变色器件中, 其有与氧化铟锡(ITO)基 电致变色器件相当的响应时间, 循环 50 次后仍可电 致变色。刘星元等 ${ }^{[10]}$ 在室温下用电子束蒸镀在 PET 基底上制备集透明导电和电致变色为一体的柔性 $\mathrm{WO}_{3} / \mathrm{Ag} / \mathrm{WO}_{3}$ 薄膜, 具有优良的耐弯折性能和电致 变色性能, 经过 1600 次弯折, 方阻几乎没有变化。 掠角沉积是制备 ECD 的新方法, 刘星元等 ${ }^{[11]}$ 研究 还表明蒸发掠射角 $75^{\circ}$ 时, $\mathrm{WO}_{3}$ 薄膜所具有的纳米 
柱结构可以释放内应力, 实现良好的耐弯折性能, 镀在 PET-ITO 柔性基底可得到柔性电致变色薄膜, 弯折 1000 次后, 变色性能无明显降低。

磁控溅射技术也可用于沉积氧化铇。2017 年, Esin 等 ${ }^{[12]}$ 将 $\mathrm{WO}_{3}$ 薄膜沉积到柔性基板上，厚度 $465 \mathrm{~nm}$ 时 ECD 有快速的响应时间。2017 年, Oksuz 等 ${ }^{[13]}$ 将 ITO 或 Pt 和 $\mathrm{WO}_{3}$ 薄膜层分别用作导电材料 和电致变色材料，制备了基于羊毛纺织品基材的电 致变色器件, 性能符合预期。在全固态 ECD 方面, 2015 年, フ训刚等 ${ }^{[14]}$ 在室温下通过磁控溅射工艺在 柔性 PET-ITO 基底上制造了结构为 $\mathrm{ITO} / \mathrm{NiO}_{x} / \mathrm{LiTaO}_{3} /$ $\mathrm{WO}_{3} / \mathrm{ITO}$ 的互补器件, 具有高的光学调制和着色效 率。2016 年, Tang 等 ${ }^{[15]}$ 将有效面积 $24 \mathrm{~cm} \times 18 \mathrm{~cm}$ 的 ITO $/ \mathrm{WO}_{3} / \mathrm{Nb}_{2} \mathrm{O}_{5} / \mathrm{NiVO}_{x} / \mathrm{ITO}$ 全固态整体式 ECD 通 过磁控溅射沉积在 PET 基板上, 可以承受 8000 多次 循环和 $7.5 \mathrm{~cm}$ 的弯曲曲率半径。Cannavale 等 ${ }^{[16]}$ 利 用全氟磺酸(Nafion)膜作为固态电解质, 开发了一 种室温制备全固态柔性变色器件的工艺, 着色效率 高达 $139 \mathrm{~cm}^{2} \cdot \mathrm{C}^{-1}$, 并且耐受 1000 次变色循环。

相较于以上的物理沉积技术, 溶液法成本低, 易实现掺杂和大面积制备。2017 年, 刘建伟等 ${ }^{[4]}$ 将 溶剂热法制备的 $\mathrm{W}_{18} \mathrm{O}_{49}$ 纳米线与 $\mathrm{Ag} \mathrm{NWs}$ 在 PET 基底上共组装得到柔性变色薄膜, 如图 1 所示, 在 $1.2 \mathrm{~cm}$ 曲率半径下弯曲 1000 次后薄膜仍具有稳定
的导电性和电致变色性能。2019 年, 刘向阳等 ${ }^{[17]}$ 通 过脉冲电化学沉积方法在柔性膜上制备了多孔 $\mathrm{WO}_{3} / \mathrm{Ag} \mathrm{NWs} / \mathrm{WO}_{3}$ 膜, 三明治结构不仅保护 $\mathrm{Ag}$ 网 络免受电解质的氧化和腐蚀, 还有利于电解质的渗 透并减轻机械应力。 2018 年, 郭文喜等 ${ }^{[18]}$ 提出了一 种裂纹图案技术制造矩形 $\mathrm{Ag}$ 导电网络, 应用于 $\mathrm{WO}_{3}$ 基柔性 ECD, 具有出色的机械强度和接近于刚 性 ECD 商业标准的光电性能。

\subsection{2 氧化钼}

氧化钼电化学稳定性不如氧化铇, 但也得到了 广泛的研究。2016 年, 刘星元等 ${ }^{[19]}$ 在柔性 PET 基底 上制备双功能 $\mathrm{MoO}_{3} / \mathrm{Ag} / \mathrm{MoO}_{3}$ 薄膜, 具有高的着色 效率和光学对比度, 与 $\mathrm{PET} / \mathrm{ITO} / \mathrm{MoO}_{3}$ 相比有较好 的耐弯折性能和循环稳定性。2016 年, Seo 等 ${ }^{[20]}$ 研 究展示了适用于柔性电致变色的石墨烯基氧化钼纳 米杂化物 mRGO- $\mathrm{MoO}_{3-x}$ 可通过 Langmuir-Blodgett 方法高覆盖率沉积在各种基材上, 不仅变色前有高 透射率，在硬质和柔性基材上均能够表现出优异的 电致变色行为。

\subsection{3 氧化镍}

氧化镍为研究较为普遍的阳极电致变色材料之 一, 常见于电致变色器件的对电极层中 ${ }^{[21]}$ 。2016 年, フ训刚等 ${ }^{[22]}$ 采用直流磁控溅射技术在不同氧分压 的柔性祄底上沉积氧化镍薄膜, 并在柔性 PET 上依
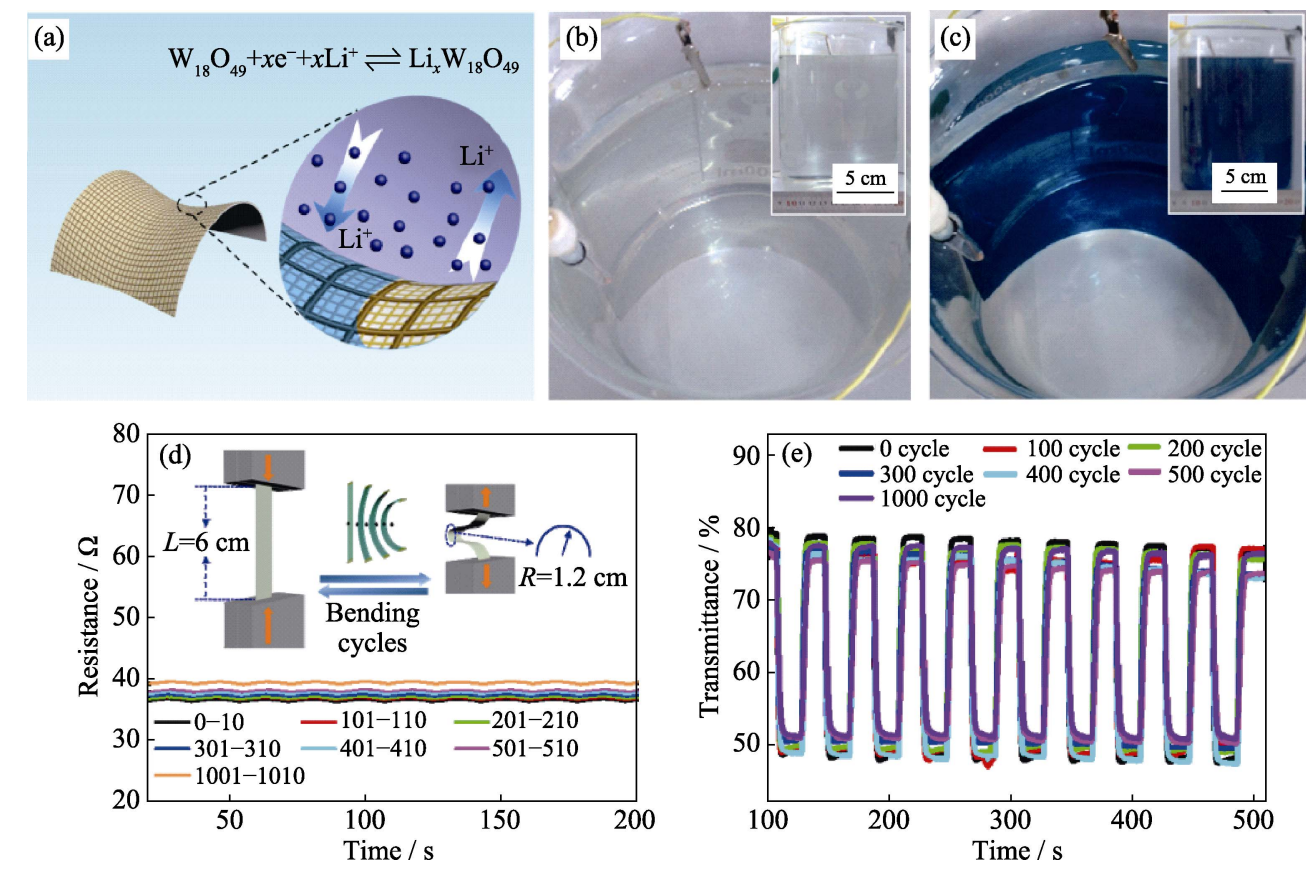

图 1 溶剂热法制备的 $\mathrm{W}_{18} \mathrm{O}_{49}$ 纳米线与 $\mathrm{Ag} \mathrm{NWs}$ 在 PET 基底上共组装得到柔性变色薄膜 ${ }^{[4]}$

Fig. $1 \mathrm{~W}_{18} \mathrm{O}_{49}$ nanowires and $\mathrm{Ag}$ NWs by solvothermal preparation co-assembled on PET substrate to obtain flexible color-changing film ${ }^{[4]}$

(a) Schematic illustration of the curved $\mathrm{Ag}$ and $\mathrm{W}_{18} \mathrm{O}_{49} \mathrm{NW}$ film with electrochromic property; (b,c) The film attached on the curved surface of the beaker before (bleached state) and after (colored state) applying voltage; (d) In situ electrical resistance change of flexible electrochromic film after 0, 100, 200, 300, 500, and 1000 bending cycles; (e) Switching behaviors of the ECD after 0, 100, 200, 300, 400, 500, and 1000 bending cycles 
次真空沉积多层堆叠 $\mathrm{ITO} / \mathrm{NiO}_{x} / \mathrm{Ta}_{2} \mathrm{O}_{5}: \mathrm{H} / \mathrm{WO}_{3} / \mathrm{ITO}$, 获得 $60 \%$ 的光学调制范围 (550 nm 处)和良好的循环 特性(125 个循环), 并通过静态弯曲和纳米划痕试 验验证了机械性能。

\subsection{4 复合及其他金属氧化物}

复合金属氧化物的特性备受人们关注，并应用 于柔性电致变色器件之中。2017 年, 李效民等 ${ }^{[23]}$ 在 柔性透明 PET- $\mathrm{ZnO}: \mathrm{Al}$ 基底上生长 $\mathrm{WO}_{3} / \mathrm{ZnO}$ 纳米复 合结构, 结果表明与 $\mathrm{ZnO}$ 复合后提高了 $\mathrm{WO}_{3}$ 比表面 积, 缩短了 $\mathrm{Li}^{+}$离子扩散距离, 器件具有大的光调制 范围(68.2\%)和较高的着色效率 $\left(80.6 \mathrm{~cm}^{2} \cdot \mathrm{C}^{-1}\right)$ 。 2017 年, Milliron 等 ${ }^{[24]}$ 将多金属氧化铌簇填充到氧化铇 介孔薄膜之中, 化学冷凝制得 $\mathrm{WO}_{x}-\mathrm{NbO}_{x}$ 复合膜, 无需任何退火步骤即可实现柔性基板上的电致变色 膜, 且具有高切换速度, 可稳定循环 2000 多次。

2020 年, 韩国电子部品研究院的 Han 等 ${ }^{[25]}$ 通过 调控最佳掺杂铇配比 $(x=0.024)$ 的镍 $\left(\mathrm{Ni}_{1-x} \mathrm{~W}_{x}\right)$ 氧化物 薄膜作为电致变色器件的对电极, 与 $\mathrm{WO}_{3}$ 薄膜分别 沉积在 c-ITO(结晶态氧化铟锡)/石墨烯/PET 电极, 制备了柔性器件。并在 1000 次脉冲电位循环中保持 了稳定的 $40 \%$ 的光学调制范围。即便在弯曲状态, 该 FECD 器件的颜色也会从浅黄色 $(-1.5 \mathrm{~V})$ 变为深 蓝色 $(+1.5 \mathrm{~V})$, 对机械弯曲展现良好的稳定性能。

此外, 其他金属氧化物也得到一定的研究。加 拿大麦克敦大学的 Djaoued 等 ${ }^{[26]}$ 提出 “动态硬模板” 渗透策略, 借助聚苯乙烯纳米球除去高温结晶步骤, 在柔性 PET-ITO 基底上制备了大面积无裂纹的纳米 锐钛矿型二维反蛋白石结构二氧化钛薄膜, 并作为 活性电极成功应用于柔性电致变色器件中。2018 年, 张洪亮等 ${ }^{[27]}$ 通过在双层石墨烯/PET 基板上进行电 化学沉积制备柔性多色电致变色氧化钒 $\left(\mathrm{V}_{2} \mathrm{O}_{5}\right)$ 薄膜, 在 $800 \mathrm{~nm}$ 波长达到 $555.83 \mathrm{~cm}^{2} \cdot \mathrm{C}^{-1}$ 的超高着色效率 和 $68.94 \%$ 的优良透射率调制。

\section{2 普鲁士蓝}

普鲁士蓝具有多种颜色变化, 其响应时间短, 循环寿命长, 且可以通过电沉积法、涂覆法等与柔 性基底结合。普鲁士蓝常与金属氧化物构成互补的 变色系统, 以提高 ECD 的性能。2017 年, Wang 等 ${ }^{[28]}$ 使用 $\mathrm{WO}_{3}$ 作为阴极着色膜, 合成普鲁士蓝纳米颗粒 并涂覆在 ITO 基底上, 并利用聚甲基丙烯酸甲酯一 丁二腈(PMMA-SN)复合聚合物制成准固态 ECD。 2018 年, 李敬等 ${ }^{[29]}$ 采用柔性金/普鲁士蓝电极作为 指示电极, 组装能量和传感元件, 制得简易的自供 电可穿戴生物传感器。如图 2 所示, 通过普鲁士蓝的 颜色变化, 可用肉眼即时监测汗液中的离子强度。

与光电探测器等功能器件结合也是 ECD 发展 方向之一。2018 年, 赵传熙等 ${ }^{[30]}$ 分别选择钛䇴上的 $\mathrm{TiO}_{2}$ 纳米管和柔性 PET-ITO 上的普鲁士蓝作为光电 阳极和电致变色对电极, 集成柔性紫外光电探测器, 不仅可以在多次弯曲周期内稳定运行, 而且无需外 部电源即可通过颜色变化显示紫外线强度。表 1 列 举了几种典型无机柔性电致变色器件的性能对比。

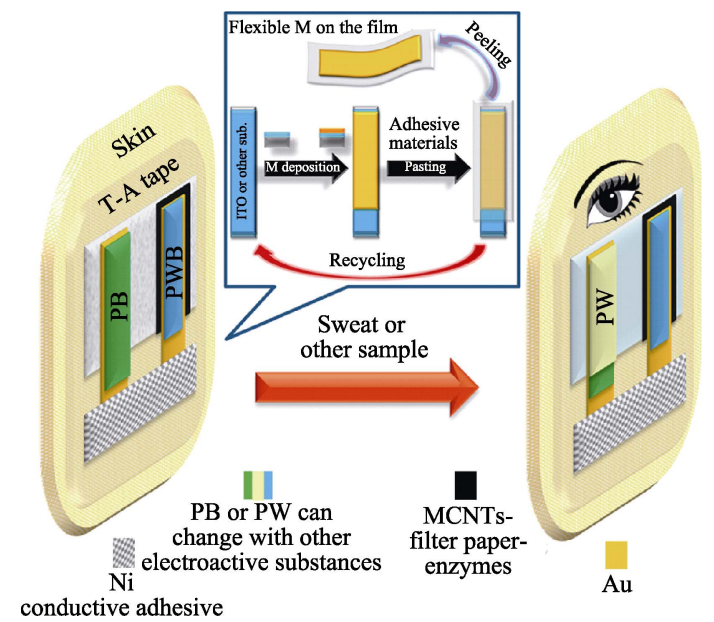

图 2 基于普鲁士蓝的柔性传感器 [29]

Fig. 2 Flexible sensor based on prussian blue ${ }^{[29]}$

表 1 无机电致变色器件性能比较

Table 1 Performance comparison of inorganic FECD

\begin{tabular}{|c|c|c|c|c|c|c|}
\hline Materials & $\begin{array}{l}\text { Switching } \\
\text { time/s }\end{array}$ & $\begin{array}{c}\text { Coloration } \\
\text { efficiency } /\left(\mathrm{cm}^{2} \cdot \mathrm{C}^{-1}\right)\end{array}$ & $\begin{array}{l}\text { Transmittance } \\
\text { modulation/\% }\end{array}$ & Stability/cycles & $\begin{array}{l}\text { Bending } \\
\text { radius } / \mathrm{mm}\end{array}$ & Ref. \\
\hline $\mathrm{W}_{18} \mathrm{O}_{49}$ & $10.3 / 7.4$ & 35.7 & 60 & 1000 & 12 & {$[4]$} \\
\hline $\mathrm{WO}_{3} / \mathrm{Ag} / \mathrm{WO}_{3}$ & $11 / 10.5$ & 136 & 53 & 3000 & 15 & [10] \\
\hline $\mathrm{WO}_{3}$ & $3.5 / 8.4$ & 60.1 & 73.3 & 200 & 5 & [11] \\
\hline $\mathrm{WO}_{3}-\mathrm{NiVO}_{x}$ & $6 / 5$ & - & 42 & 8000 & 75 & [15] \\
\hline $\mathrm{WO}_{3}$ & 30 & 139 & 49 & 1000 & - & [16] \\
\hline $\mathrm{WO}_{3}$ & $9 / 19$ & 58.95 & 89.7 & 300 & 2 & [17] \\
\hline $\mathrm{MoO}_{3}$ & $6.2 / 10.9$ & 34.7 & 27.7 & 150 & 11 & [19] \\
\hline $\mathrm{NiO}_{x}-\mathrm{WO}_{3}$ & - & $20-35$ & 60 & 125 & 36 & [22] \\
\hline $\mathrm{WO}_{3}-\mathrm{ZnO}$ & $6.2 / 2.8$ & 80.6 & 68.2 & - & - & [23] \\
\hline Prussian blue $-\mathrm{WO}_{3}$ & $<10$ & - & 52.4 & 2250 & - & [28] \\
\hline
\end{tabular}




\section{2 有机柔性电致变色器件}

有机电致变色材料的研究虽然起步稍晚, 但由 于响应时间短、廉价易得、易加工、颜色变化种类 丰富等优点得到了广泛研究 ${ }^{[31]}$ 。常把有机电致变色 材料分为导电聚合物、氧化-还原型、金属有机鳌合 物三种, 可分别通过改变掺杂程度、转换价态、能 级分裂实现电致变色。在有机柔性电致变色器件的 制备中同样存在不少的挑战，如开发新的导电基底 解决泄露和易燃的问题、避免电解质沉积钝化电极 提高器件的长期使用性等。

\section{1 导电聚合物}

导电聚合物是通过掺杂获得导电性的含共轭结 构的大分子, 施加电压可改变其掺杂程度及能带结 构, 从而改变其对入射光的吸收特征。其合成工艺 简便、易加工修饰、颜色可调性强。在柔性电致变 色器件方面, 此类材料不仅可用作电致变色层, 还 可以胜任柔性电极，故应用前景十分广阔。

\subsection{1 聚苯胺及其衍生物}

聚苯胺(PANI)可通过模板聚合、电沉积法等在 柔性导电基底上制备, 得到性能优良的柔性 ECD。 2017 年, Diaz-Sanchez 等 ${ }^{[32]}$ 使用酶介导的聚没食子 酸作为聚苯胺聚合模板实现了基于聚苯胺的柔性电 致变色设备, 在 $650 \mathrm{~nm}$ 波长处光学对比度为 $22 \%$, 寿命高达 700 个循环。2019 年, 程文龙等 ${ }^{[33]}$ 通过自 组装垂直金纳米线 (v-AUWs) 和电沉积聚苯胺组装 了第二皮肤状电致变色超级电容器, 具有很大的柔 韧性，在多次手部运动和皮肤变形下，其性能下降 的幅度可以忽略不计。

聚苯胺也是优秀的电极材料。2019 年, $\mathrm{Lu}$ 等 ${ }^{[34]}$ 报告了在高弯曲性 PANI-CNT(碳纳米管)/PET 导电 薄膜上电沉积 PANI 所得 PANI/PANI-CNT/PET 的性 能与 PANI/ITO/PET 相当, 而经过 100 次弯曲后可以 更好地保留其初始变色性能。

2018 年, 汪浩等 ${ }^{[35]}$ 采用电沉积方法, 在柔性 PET-ITO 基底上制备了具有改性纳米结构的柔性 PANI 薄膜, 获得了很好的机械柔韧性, $630 \mathrm{~nm}$ 波长 处具有 $80.9 \mathrm{~cm}^{2} \cdot \mathrm{C}^{-1}$ 的高着色效率和显著的多色性 能。2019 年，曹亚等 ${ }^{[36]}$ 利用 PET-ITO 作为透明导电 基底, 喷涂单分散的 $\mathrm{SiO}_{2} / \mathrm{PANI}$ 核/壳纳米球用作电 致变色材料, 所得柔性 ECD 弯曲循环 500 次后性能 基本保持。2020 年, 李圭等 ${ }^{[37]}$ 以液体电解质负载高 孔隙率的聚醚醚酮 (PEEK) 多孔膜作为新型电解质 材料, 将聚苯胺薄膜沉积在多孔金电极上, 制备了
柔性红外电致变色薄膜, 具有优异的红外发射率 调节能力, 快速的开关时间 $(<10 \mathrm{~s})$ 和良好的循环稳 定性。

\subsection{2 聚噻吩及其衍生物}

聚噻吩及其衍生物同样具有优秀的电学性能, 例如掺杂和去掺杂时的优良稳定性、结构多样性等。 近年来人们对聚-3,4-乙烯二氧噻吩(PEDOT)进行了 广泛而深入的研究。2015 年, 彭海琳等 ${ }^{[38]}$ 通过连续 大规模卷对卷生产石墨烯/银纳米线复合透明导电 电极, 并利用 PEDOT 作为变色层制备出柔性 ECD, 在弯曲情况下可以毫无困难地工作。

2017 年, Kumar 等 ${ }^{[39]}$ 报道了涂在柔性膜上的 PEDOT: PSS(聚苯乙烯磺酸盐)膜的性能经对甲苯磺 酰胺-二甲基亚砜(PTSA-DMSO)处理，可作为用于 $\mathrm{ECD}$ 应用的电极(图 3), 与基于 ITO 电极的 $\mathrm{ECD}$ 进 行比较在电化学循环和多次机械弯曲测试中均表现 出更卓越的稳定性。2018 年, Kim 等 ${ }^{[40]}$ 通过喷涂法 制备了基于银纳米线和 PEDOT: PSS 的高透明导电 电极, 利用 $\mathrm{EC}$ 凝胶的弹性特性, 在塑料基底上实现 了柔性 ECD。2017 年, Chuangchote 等 ${ }^{[41]}$ 获得了透 明的导电 PEDOT 柔性电极, 用于制造柔性电致变 色器件, 聚(3-己基噻吩)用作活性层, 施加较小电压 $( \pm 3 \mathrm{~V})$ 即从透明的浅蓝色变为紫色。

\section{2 氧化一还原型化合物}

此类化合物常常是含共轭体系及富电子杂原子 的有机小分子，通过可逆的氧化还原过程实现电致 变色, 主要有联吡啶、四噻富瓦烯等及其衍生物。 紫精是联吡啶的一种衍生物。2017 年, Moon 等 ${ }^{[42]}$ 将二甲基二茂铁作为阳极物质掺入单庚基紫精 $\left(\mathrm{MHr}^{+}\right)$和二庚基紫精 $\left(\mathrm{DHV}^{2}{ }^{+}\right)$凝胶中, 获得良好的 着色效率，并制备了基于凝胶橡胶特性的可显示多 种颜色的可弯曲 ECD。

含紫精衍生物的 $\mathrm{EC}$ 凝胶是当前研究的热点之 一。2018 年, Moon 等 ${ }^{[43]}$ 使离子凝胶通过引入乙基紫 精而功能化并应用于 ECD, 由于凝胶的机械性能, $\mathrm{ECD}$ 在压缩应变和拉伸应变下均具有出色的弯曲
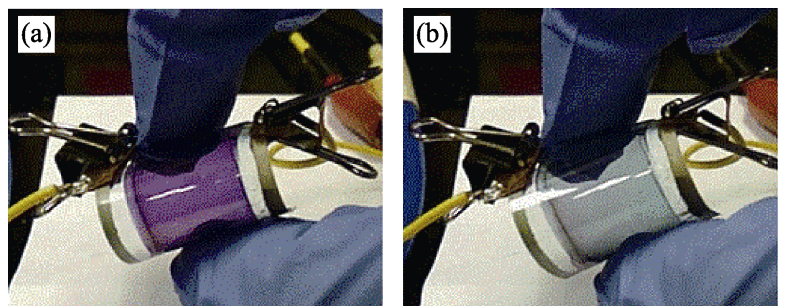

图 3 基于 PEDOT:PSS PD 电极的电致变色器件 ${ }^{[39]}$ Fig. 3 Flexible ECD based on PEDOT:PSS PD electrodes ${ }^{[39]}$ (a) Colored state; (b) Bleached state 
耐久性。2019 年, Myoung 等 ${ }^{[44]}$ 实现了图 4 所示含单 庚基紫精, 二庚基紫精(DHV)和二苯基紫精(DPV) 的基于离子液体的 $\mathrm{EC}$ 凝胶, 在 $10 \mathrm{~mm}$ 的弯曲半径 下进行 1000 次机械弯曲测试之后, 亚像素化的柔性 ECD 仍显示出高耐久性。

2017 年, Vinuales 等 ${ }^{[45]}$ 提议将基于紫精的电 致变色混合物掺入纸基，指出使用纸张具有同质性， 使用寿命长(氧化还原循环超过 1000 次)和抗弯曲能 力强的好处。也有研究人员将紫精衍生物与其他有 机电致变色材料复合, 制得性能优异的 ECD。

2015 年, Lodge 等 ${ }^{[46]}$ 将甲基紫精和二茂铁作为阳 极物质添加到 $\mathrm{EC}$ 凝胶中, 可以直接将其涂覆到 塑料上，形成简单的柔性 ECD, $0.7 \mathrm{~V}$ 时着色效率 为 $105 \mathrm{~cm}^{2} \cdot \mathrm{C}^{-1}$, 在空气中 $24 \mathrm{~h}$ 内仍具有良好的稳 定性。

\section{3 金属有机螯合物}

金属离子与配体形成的有机螯合物中金属离子 能级分裂, 落在可见光范围内的能级差 $\Delta$ 使其呈现 能级差 $\Delta$ 的互补色, 故可作 ECD 中的电致变色材

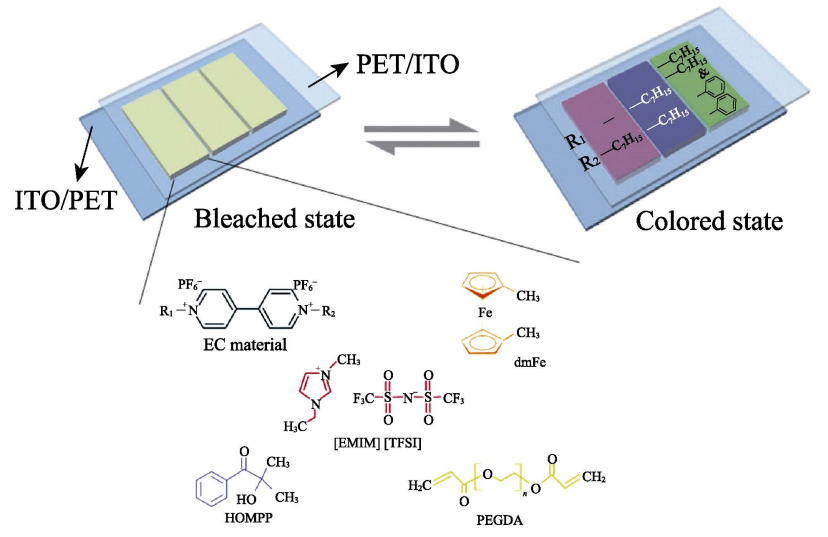

图 4 基于紫精的多色柔性电致变色器件 ${ }^{[44]}$

Fig. 4 Flexible multicolor ECD based on viologen ${ }^{[44]}$
料使用。

2018 年, 李听等 ${ }^{[47]}$ 将亚铁离子与三联吡啶及其 衍生物配位聚合得到金属超分子聚合物 $\mathrm{FeL}$, 滴涂 成为薄膜, 制成结构为 PEN(聚萗二甲酸乙二醇酯)ITO/FeL/Gel electrolyte/PEN-ITO 的柔性 ECD, 对比 度 $41 \%$, 着色效率 $299.8 \mathrm{~cm}^{2} \cdot \mathrm{C}^{-1}$, 着色和褪色时间 为 $3.6 \mathrm{~s} / 7.3 \mathrm{~s}$, 达到了实用水平。2015 年, Higuchi 等 ${ }^{[48]}$ 将具有两种颜色的金属超分子聚合物(MEPE) 溶液喷墨印刷得到 EC 薄膜, 与固体透明薄膜电解 质和透明导电薄膜层压成 $\mathrm{ECD}$, 在弯曲条件下仍具 有 $30.1 \%$ 的高光学对比度。2016 年, Freire 等 ${ }^{[49]}$ 报道 了两种聚 $[\mathrm{Ni}($ salen)]型电活性聚合物薄膜作为新型 电致变色材料, 电沉积到 ITO-PET 柔性基板上, 具 有良好的稳定性和光学对比度。表 2 列举了几种典 型有机柔性电致变色器件的性能对比。

\section{3 无机/有机复合柔性电致变色器件}

无机和有机电致变色材料属于优势互补的关系, 因此人们致力于研发同时包含各自优点的复合电致 变色材料, 并将其应用于柔性 ECD 中。将金属氧化 物与导电聚合物复合是很重要的一个研究方向, 常 通过喷涂法等工艺实现。2016 年, 王宏志等 ${ }^{\left[{ }^{[0]}\right.}$ 在超 薄 PET 基底上用喷涂法构建 $\mathrm{Ag} N W s-\mathrm{W}_{18} \mathrm{O}_{49} \mathrm{NWs}$ 网络, 并以藻酸/聚 (多巴胺) 复合物 (Aa-PDA) 和 PEDOT:PSS 层分别用作粘合剂和电荷平衡层, 实现 了轻质、高度可弯曲和可折叠的 $\mathrm{EC}$ 膜, 可进行 500 次弯曲或 100 次折叠循环。 2019 年, 李丽东等 ${ }^{[1]}$ 将 PANI 和 $\mathrm{WO}_{2.7} \mathrm{NWs}$ 复合获得电致变色电极, 喷涂 金纳米粒子提高导电性, 并合成新型自愈合水凝胶 作为固体电解质, 组装了具有电致变色和自修复特 性的柔性超级电容器。

表 2 有机电致变色器件性能比较

Table 2 Performance comparison of organic FECD

\begin{tabular}{lcccccc}
\hline \multicolumn{1}{c}{ Materials } & $\begin{array}{c}\text { Switching } \\
\text { time/s }\end{array}$ & $\begin{array}{c}\text { Coloration } \\
\text { efficiency } \\
/\left(\mathrm{cm}^{2} \cdot \mathrm{C}^{-1}\right)\end{array}$ & $\begin{array}{c}\text { Transmit- } \\
\text { tance modu- } \\
\text { lation/\% }\end{array}$ & Stability & $\begin{array}{c}\text { Bending } \\
\text { radius/mm }\end{array}$ & Ref. \\
\hline PANI & $40 / 20$ & 22.9 & 34 & 200 cycles & 6 & {$[34]$} \\
PANI & $3.9 / 2.61$ & 80.9 & 49 & 500 cycles & 10 & {$[35]$} \\
PEDOT & $4.1 / 3.4$ & - & 21 & $10000 \mathrm{cycles}$ & 20 & {$[38]$} \\
PEDOT: PSS & $4.6 / 2$ & 429 & 45 & $4000 \mathrm{cycles}$ & - & {$[39]$} \\
ethyl viologen & $41 / 395$ & 117.7 & 92.1 & $60000 \mathrm{~s}$ & 12.5 & {$[43]$} \\
monoheptyl-viologen/diheptylviologen/diphenyl-viologen & $20 / 34$ & 87.3 & 25 & $3600 \mathrm{~s}$ & 10 & {$[44]$} \\
FeL & $3.6 / 7.3$ & 299.8 & 41 & $250 \mathrm{cycles}$ & - & {$[47]$} \\
MEPE & $2 / 26$ & 445 & 40.1 & - & 10 & {$[48]$} \\
Poly[Ni(salen)]-type polymer & $157 / 145$ & 130.4 & 88.7 & $3000 \mathrm{cycles}$ & - & {$[49]$} \\
\hline
\end{tabular}


2016 年, Lee 等 ${ }^{[52]}$ 在银栅格/ PEDOT: PSS 杂化 膜上涂覆一层 $\mathrm{WO}_{3}$ 纳米颗粒制备 $\mathrm{ECD}$, 在 $633 \mathrm{~nm}$ 处有 $81.9 \%$ 的光学调制, 优秀的响应速度和着色效 率, 更获得了出色的电化学循环稳定性和机械柔韧 性。如图 5 所示, 在 1200 次弯曲循环后, 光调制仅 有 $7.5 \%$ 的衰减。2017 年, 赵九蓬等 ${ }^{[53]}$ 制作了新型 $\mathrm{WO}_{3} \cdot 2 \mathrm{H}_{2} \mathrm{O} / \mathrm{PEDOT}$ 膜, 由瞬态加热方法牢固地固定 在使用 $\mathrm{Ag}$ 作为导电层的 $\mathrm{EVA}$ (乙烯一醋酸乙烯共聚 物)/PET 电极上, 该电致变色膜机械坚固, 可以扭曲, 折叠和褶皱, 而不会降低性能, 且与 $\mathrm{WO}_{3} \cdot 2 \mathrm{H}_{2} \mathrm{O}$ 膜 相比实现了更高的性能。2016 年, Vinuales 等 ${ }^{[54]}$ 报 道基于仅在 $120{ }^{\circ} \mathrm{C}$ 进行热处理的紫精改性 $\mathrm{TiO}_{2}$ 纳 米结构薄膜的柔性塑料电致变色器件, 还报道了与 塑料基材相容性更优的紫精的合成，最后展示了大 面积全固态设备 $(40 \mathrm{~cm} \times 30 \mathrm{~cm})$, 证明该技术适用 于生产大面积塑料 ECD。2018 年, Kang 等 ${ }^{[55]}$ 设计 了一种高性能超柔性新型混合透明电极(AgNWS/ PEDOT:PSS), 以低温合成 $\mathrm{Ni}(\mathrm{OH})_{2}$ 和聚乙烯亚胺聚 氧乙烯醚(PEIE)复合材料为电致变色层, 用于制备 双功能电致变色-超级电容器件。该 FECD 器件在 10000 次充放电循环下表现出稳定的循环稳定性, 在 $633 \mathrm{~nm}$ 处的着色效率高达 $517 \mathrm{~cm}^{2} \cdot \mathrm{C}^{-1}$, 开关速 度快 $(<0.6 \mathrm{~s})$ 。此外，在弯曲半径为 $1 \mathrm{~mm}$ 的情况下，

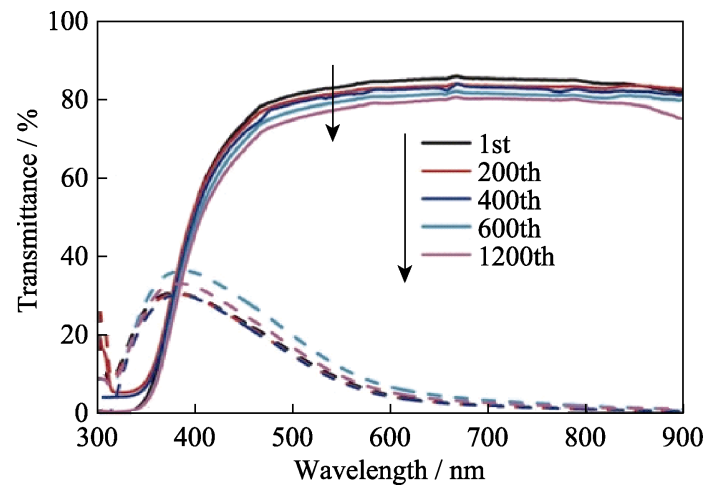

图 5 银栅格/PEDOT:PSS/ $\mathrm{WO}_{3}$ 复合膜弯曲循环后的变色性 能 ${ }^{[52]}$

Fig. 5 Electrochromic performance of the Ag grid/PEDOT: $\mathrm{PSS} / \mathrm{WO}_{3}$ film after bending ${ }^{[52]}$
即使在 8000 次弯曲循环后，电容保持率仍达到 90\%, 并且可以容忍 15 次禇皱而没有明显的退化，保持优 异的机械坚固性和灵活性。表 3 列举了几种典型无 机/有机复合柔性电致变色器件的性能对比。

\section{4 其他材料柔性电致变色器件}

近年来, 新型(柔性)电致变色器件中不断涌现 出新材料，如微孔金属一有机框架 (Microporous metal-organic frameworks) ${ }^{[56-57]}$ 、有机一卤化物杂化钙 铁矿(Organic-halide hybrid perovskites) ${ }^{[58]}$ 、二维过渡 金属碳/氮化物(MXenes) ${ }^{[59]}$ 等，极大地扩充了电致 变色材料的选择范围。例如, 2019 年 Tan 等 ${ }^{[60]}$ 展示了 使用 Guest@MOF 概念来设计电致变色薄膜, DHTP@Zn-MOF-74 的薄膜在柔性 PET-ITO 基底上 生长, 可在无色和品红色之间可逆切换, 为发现具 有可调节特性的新 Guest@MOF 电致变色系统打开 大门。

\section{5 可拉伸电致变色器件}

从技术上说，赋予刚性电致变色器件可拉伸性 比可弯曲性更难实现，人们不断将电致变色器件顺 着刚性、柔性、可拉伸性的发展趋势推进，在可拉 伸 ECD 方面也取得了丰硕的成果。可拉伸电致变色 器件要求在各种长周期的机械变形(弯曲、折叠和拉 伸)下仍保持高性能, 研发主要集中在平衡导电性、 光学透明度和机械拉伸性的重大挑战上。

2018 年，郭文喜等 ${ }^{[61]}$ 成功地构筑 $\mathrm{WO}_{3} / \mathrm{Ag}$ NWs/PEDOT:PSS 复合柔性 ECD 电极, 重复弯曲 5000 次或拉伸至 $100 \%$ 形变量甚至在扭曲 $720^{\circ}$ 时依 然保持良好的导电性, 并首次在厚度仅为 $10 \mu \mathrm{m}$ 的 PE 家用保鲜膜基底表面制备电致变色器件，如图 6 所示。2019 年，刘贵生等 ${ }^{[2]}$ 制备了基于银纳米线/ 聚二甲基硅氧烷(Ag NWs/PDMS)混合电极的新型 可拉伸双极性电致变色器件, 电致变色功能由基于

表 3 无机/有机复合电致变色器件性能比较

Table 3 Performance comparison of inorganic/organic composite FECD

\begin{tabular}{|c|c|c|c|c|c|c|}
\hline Materials & $\begin{array}{l}\text { Switching } \\
\text { time/s }\end{array}$ & $\begin{array}{l}\text { Coloration } \\
\text { efficiency } \\
/\left(\mathrm{cm}^{2} \cdot \mathrm{C}^{-1}\right)\end{array}$ & $\begin{array}{l}\text { Transmittance } \\
\text { modulation } / \%\end{array}$ & Stability/cycles & $\begin{array}{l}\text { Bending } \\
\text { radius } / \mathrm{mm}\end{array}$ & Ref. \\
\hline $\mathrm{W}_{18} \mathrm{O}_{49}$ NWs-PEDOT:PSS & $18.2 / 6.6$ & 118.1 & 34.3 & - & 2.5 & {$[50]$} \\
\hline PEDOT:PSS- $\mathrm{WO}_{3}$ & $1.9 / 2.8$ & 124.5 & 81.9 & 2000 & 20 & {$[52]$} \\
\hline $\mathrm{WO}_{3} \cdot 2 \mathrm{H}_{2} \mathrm{O}-\mathrm{PEDOT}$ & $4.4 / 2.6$ & 180.2 & 63.1 & - & - & [53] \\
\hline Viologen- $\mathrm{TiO}_{2}$ & $8 / 6$ & 226 & 53 & 1000 & - & {$[54]$} \\
\hline 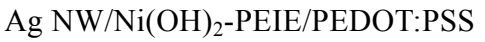 & $0.3 / 0.6$ & 517 & 30 & 100 & 1 & {$[55]$} \\
\hline
\end{tabular}




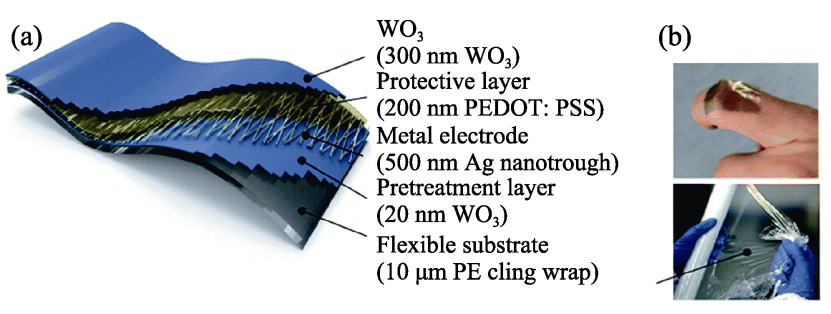

图 6 基于聚乙烯保鲜膜 $\mathrm{PE}$ 的 $\mathrm{ECD}^{[61]}$

Fig. 6 ECD on household PE cling wrap ${ }^{[61]}$

(a) Schematic illustration of the structure of the PE cling wrap-based hybrid EC film; (b) The color-changing e-skin (top) and PE cling wrap (bottom)

三苯胺衍生物和庚基紫精的双极性体系实现。

可拉伸 ECD 要求各部分配件都具备可拉伸性 且配合紧密。2017 年, 刘贵生等 ${ }^{[63]}$ 使用具有疏水性 表面的基底制备 $\mathrm{Ag} \mathrm{NWs} / \mathrm{PDMS}$ 电极，可以拉伸、 扭曲和折叠而不会显著损失导电性，基于此制造的 新型弹性体 $\mathrm{HV}$ 电致变色器件表现出优异的电致变 色性能, 在 100 个开关周期后仍可改变颜色。2018 年, Varghese 等 ${ }^{[64]}$ 报道了基于聚二乙炔(PDA)功能化的 碳纳米管(CNT)在柔性、可拉伸和可编织器件方面 的潜力, 其保留了聚合物固有的多刺激色响应(蓝色 到红色), 并由导电 CNT 在 PDA 中引起电致变色。

可拉伸电致变色超级电容器充放电过程中随电 压变化显示不同颜色反映储能状态，受到人们的青 睐。2019 年, $\mathrm{Han}$ 等 ${ }^{[65]}$ 基于 $\mathrm{Au} / \mathrm{Ag}$ 核壳纳米线, 双 堆叠 $\mathrm{WO}_{3}$ 纳米管/PEDOT:PSS 制备全透明的可拉伸 智能超级电容器 (图 7), 即使在机械变形下也能维 持性能, 着色效率约 $83.9 \mathrm{~cm}^{2} \cdot \mathrm{C}^{-1}$ 。2018 年, Lee 等 ${ }^{[66]}$
在弹性透明导体上喷墨印刷单层 $\mathrm{WO}_{3}$ 纳米粒子，与 聚苯胺/碳纳米管复合电极组成的设备即使拉伸到 $50 \%$ 的形变量, 也能保持出色的电致变色和能量存 储性能。

可拉伸 ECD 应用前景广阔。 2019 年, $\mathrm{Ha}$ 等 ${ }^{[67]}$ 报告了基于聚(3-甲基噻吩)和普鲁士蓝电极的可拉 伸 ECD，显示出在弯曲和 $30 \%$ 双轴拉伸下的机械稳 定性。2019 年, 陈花玲等 ${ }^{[68]}$ 通过整合可拉伸光子晶 体和形状记忆合金复合材料获得可拉伸电致变色器 件, 在 $1.0 \sim 1.5 \mathrm{~V}$ 的电压下, 可以在整个可见光范围 内实现变色，具有驱动电压低、柔顺性好、变色范 围宽、响应时间短和有效变色面积大的特点，而且 有优异的软动态显示和伪装功能, 高抗冲击性能。 2018 年，贾春阳等 ${ }^{[69]}$ 展示了一种具有仿生特性的共 聚物薄膜, 该薄膜同时整合了电致变色三苯胺和自 我修复的 Diels Alder 基团，柔性和可拉伸的共聚物 薄膜的作用就像自然变色龙皮肤，其表现出显著的 颜色变化, 并且还具有优异的自愈性能。表 4 列举 了几种典型可拉伸电致变色器件的性能对比。

\section{6 面临的挑战和发展方向}

近年来, 虽然柔性电致变色器件已经获得了较 多的研究, 但是在器件结构、器件性能及应用方面 仍然存在许多亟待解决的问题，有很大的发展空 间。下面整合了目前柔性电致变色器件中存在的问 题和挑战, 并展望了下一步研究中的可行方案。

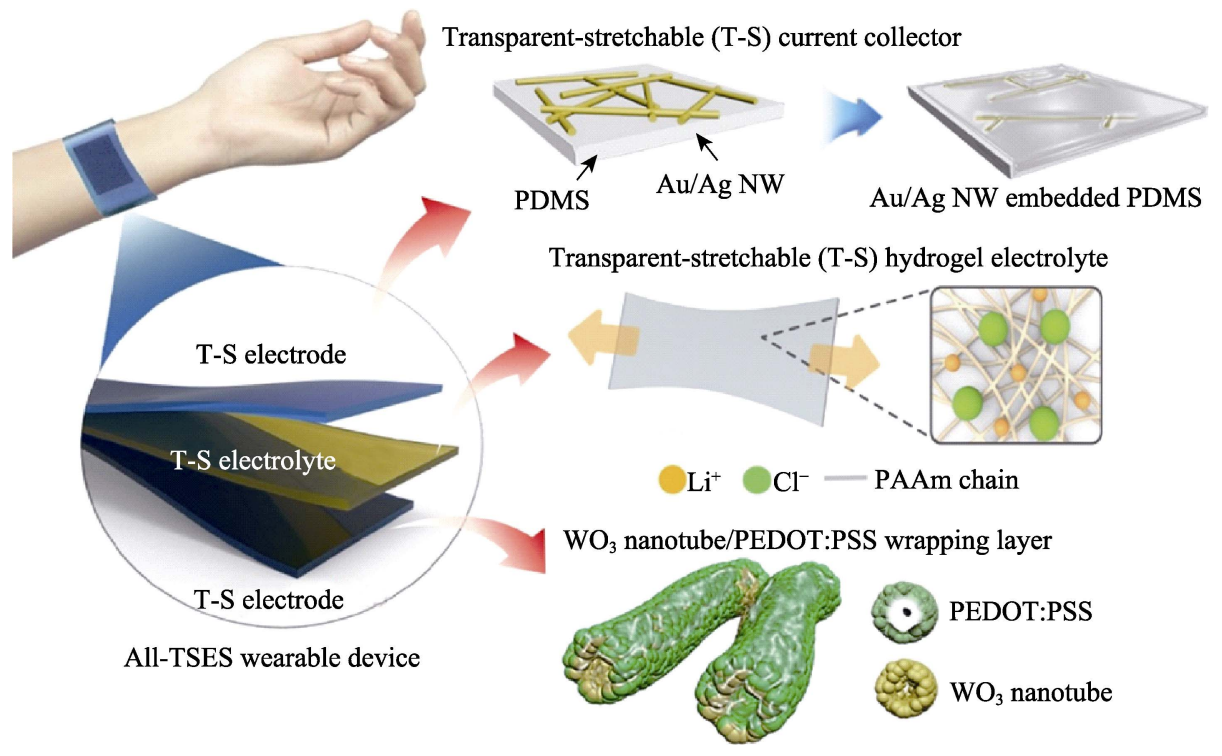

图 7 可拉伸变色超级电容器 ${ }^{[65]}$

Fig. 7 Stretchable electrochromic supercapacitor ${ }^{[65]}$ T-S: Transparent stretchable; TSES: Transparent stretchable electrochromic supercapacitor 
表 4 拉伸电致变色器件性能比较

Table 4 Performance comparison of stretchable electrochromic devices

\begin{tabular}{|c|c|c|c|c|c|c|}
\hline Materials & $\begin{array}{c}\text { Switching } \\
\text { time/s }\end{array}$ & $\begin{array}{l}\text { Coloration } \\
\text { efficiency } \\
/\left(\mathrm{cm}^{2} \cdot \mathrm{C}^{-1}\right)\end{array}$ & $\begin{array}{l}\text { Transmittance } \\
\text { modulation } / \%\end{array}$ & Stability & $\begin{array}{l}\text { Bending } \\
\text { radius } / \mathrm{mm}\end{array}$ & Ref. \\
\hline $\mathrm{WO}_{3} / \mathrm{Ag} / \mathrm{PEDOT}: \mathrm{PSS} / \mathrm{WO}_{3}$ & $1.82 / 0.75$ & - & 23 & $30000 \mathrm{~s}$ & 5 & [61] \\
\hline Heptyl Viologen & $32 / 43$ & 31.82 & 74.5 & 100 cycles & 4.8 & [63] \\
\hline $\mathrm{WO}_{3}$ nanotube / PEDOT: PSS & $<10$ & 83.9 & 37.7 & 20000 cycles & 40 & [65] \\
\hline $\mathrm{WO}_{3}$-PANI & $4.1 / 2.1$ & 75.5 & 40 & 500 cycles & 5 & [66] \\
\hline poly(3-methylthiophene)/Prussian blue & $1.3 / 1.2$ & 201.6 & 17.8 & 180 cycles & 2.5 & [67] \\
\hline copolymer DFTPA-PI-MA & $5.3 / 12.2$ & 82.2 & 60 & 100 cycles & - & [69] \\
\hline
\end{tabular}

\section{1 器件性能}

\subsection{1 电致变色性能}

电致变色性能是柔性电致变色器件最重要的内 在属性。部分报道指出在对比实验中，柔性基底制 成的电致变色器件性能不如相同结构的玻璃基底器 件优越, 其电致变色所需的外加电压较高, 响应时

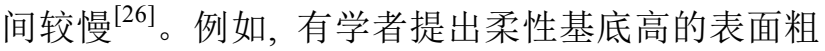
粮度可能会导致柔性 ECD 与刚性 ECD 相比呈现相 对逊色的电致变色性质 ${ }^{[10]}$ 。同时, 柔性 ECD 中常用 的金属纳米线、碳纳米管以及石墨烯等新型电极材 料也存在不少新的问题需要解决。比如银纳米线电 极容易被腐蚀或者氧化, 在多次变色循环中电极导 电性能下降迫使 ECD 的变色性能恶化。柔性 ECD 在提升变色性能方面还有很长的路要走。

\subsection{2 机械稳定性}

在多次弯折后, 不少柔性 ECD 的电致变色性能 衰减严重, 如光学调制率和循环稳定性。可能是因 为材料和基底产生一定程度的脱离, 界面故障造成 了薄膜性能的降低，因此需要开发新型材料和改良 制备技术使材料与基底紧密结合，提高 ECD 的性 能。此外, 要实现高性能可拉伸 $\mathrm{ECD}$, 除了电致变 色材料, 开发新的弹性基底和耐腐蚀的可拉伸透明 电极也十分重要。

\section{2 实际应用面临的挑战}

\subsection{1 全固态化}

全固态 ECDs 的实现是器件迈向实用化的非 常关键的一步 ${ }^{[11]}$, 柔性电致变色器件在这方面的研 究有限。对于柔性 ECD 来说, 电解质层最重要的突 破点是可弯曲和安全问题 ${ }^{[70]}$ 。采用非酸性电解质, 可能增加器件的使用寿命; 可采用柔性可自支撑的 有机-无机复合固态薄膜为电解质, 解决器件封装 难、漏液之类的安全可靠性差的问题。

\subsection{2 大面积生产}

受实验室制备技术的规模限制，制备出的样品
不仅面积不够大，而且难以实现均匀性，限制了柔 性电致变色器件应用的发展。器件的大面积制备需 要考虑卷对卷等大规模生产方式。要控制各个功能 层的均匀涂覆，可考虑对柔性基底表面进行物理或 者化学改性, 不仅有利于降低薄膜沉积缺陷, 还有 利于提高膜基附着力。

\subsection{3 成本问题}

受活性材料、封装材料和制备技术的限制，目 前柔性 ECD 有较高的商业化成本和有限的应用范 围。一种前景广阔的方式是采用化学液相合成结合 微电子打印技术、雾化沉积技术、流延法等制备复 合柔性电致变色薄膜, 不仅成本低廉、光学调制范 围好，且制备过程无需高真空环境、节约能源。但 是先合成、后涂覆的策略所得薄膜往往在基底上的 附着力逊色于物理沉积得到的薄膜, 后续需要对材 料及成膜技术进行改进。

\subsection{4 多功能化}

通过集成电致变色、光致变色、电致动、光电 探测、电化学储能等各种功能模式, 实现单一器件 的多功能化是下一代电子器件发展的重要方向, 目 前柔性电致变色器件在这一方面的研究较少, 需要 不断探索前进。

\section{7 结束语}

随着各种器件结构、加工技术和新型材料的发 展，基于其共型性好、机械强度高、成本低的优势, 柔性电致变色器件具有广阔的应用前景。本文分类 讨论了基于不同变色材料制备的柔性电致变色器件 的研究现状, 重点评述了可拉伸电致变色器件的最 新进展。然而, 柔性电致变色器件的研发当前仍然 处于初级阶段，在开发新型大面积柔性导电基底、 制备柔性电致变色薄膜、封装柔性电致变色器件等 方面尚有较大的发展空间。除了提高器件本身的电 致变色性能和机械稳定性, 器件在实际应用中也面 
临延长使用寿命等巨大的挑战。此外，柔性电致变 色器件在全固态、大面积、低成本和多功能化等方 面将成为今后的研究重点。国外学者的研究主要集 中于提升电致变色层性能、开发提高基底附着力新 技术等领域。国内学者则致力于改进祄底、导电层 和电致变色层等组成部分, 匹配各层之间的应力 关系, 力求实现器件的柔性化、轻便化, 相较而言, 在关键制备技术突破、科研与市场结合等方面与国 外仍存在不小的差距。总之, 柔性电致变色器件拥 有巨大潜力与可能性, 势必引领下一代电子技术 革命。

\section{参考文献:}

[1] GU H X, GUO C S, ZHANG S H, et al. Highly efficient, near-infrared and visible-light modulated electrochromic devices based on polyoxometalates and $\mathrm{W}_{18} \mathrm{O}_{49}$ nanowires. ACS Nano, 2018, 12(1): 559-567.

[2] FANG H J, ZHENG P Y, MA R, et al. Multifunctional hydrogel enables extremely simplified electrochromic devices for smart windows and ionic writing boards. Materials Horizons, 2018, 5(5): $1000-1007$.

[3] JIA H X, CAO X, JIN P S. Advances in inorganic all-solid-state electrochromic materials and devices. Journal of Inorganic Materials, 2020, 35(5): 511-524.

[4] WANG J L, LU Y R, LI H H, et al. Large area co-assembly of nanowires for flexible transparent smart windows. J. Am. Chem. Soc., 2017, 139(29): 9921-9926.

[5] CHEN X D, ROGERS J A, LACOUR STÉPHANIE P, et al. Materials chemistry in flexible electronics. Chemical Society Reviews, 2019, 48(6): 1431-1433.

[6] WEI W, MAN W, MA J M, et al. Electrochromic metal oxides: recent progress and prospect. Advanced Electronic Materials, 2018, 4(8): 1800185 .

[7] EH L S, TAN A W M, CHENG X, et al. Recent advances in flexible electrochromic devices: the prerequisites, challenges and prospects. Energy Technology, 2018, 6(1): 33-45.

[8] MA D Y, WANG J M. Inorganic electrochromic materials based on tungsten oxide and nickel oxide nanostructures. Science China Chemistry, 2017, 60(1): 62-70.

[9] HE H Y, CHEN A L, CHEN X Y, et al. Pretreatment optimization of silver nanowire based transparent electrode and its application in flexible electrochromic devices. Journal of Synthetic Crystals, 2015, 44(7): 149-154.

[10] LI H L, LV Y, ZHANG X, et al. High-performance ITO-free electrochromic films based on bi-functional stacked $\mathrm{WO}_{3} / \mathrm{Ag} / \mathrm{WO}_{3}$ structures. Solar Energy Materials and Solar Cells, 2015, 136:
$86-91$.

[11] XIAO L L, LÜ Y, DONG W J, et al. Dual-functional $\mathrm{WO}_{3}$ nanocolumns with broadband antireflective and high-performance flexible electrochromic properties. ACS Applied Materials \& Interfaces, 2016, 8(40): 27107-27114.

[12] EREN E, KARACA G Y, KOC U, et al. Electrochromic characteristics of radio frequency plasma sputtered $\mathrm{WO}_{3}$ thin films onto flexible polyethylene terephthalate substrates. Thin Solid Films, 2017, 634: 40-50.

[13] KOC U, KARACA G Y, OKSUZ A U, et al. RF sputtered electrochromic wool textile in different liquid media. Journal of Materials Science-Materials in Electronics, 2017, 28(12): $8725-8732$.

[14] LIU Q R, DONG G B, XIAO Y, et al. An all-thin-film inorganic electrochromic device monolithically fabricated on flexible PET/ITO substrate by magnetron sputtering. Materials Letters, 2015, 142: 232-234.

[15] TANG C J, YE J M, YANG Y T, et al. Large-area flexible monolithic ITO/ $\mathrm{WO}_{3} / \mathrm{Nb}_{2} \mathrm{O}_{5} / \mathrm{NiVO}_{x} / \mathrm{ITO}$ electrochromic devices prepared by using magnetron sputter deposition. Optical Materials, 2016, 55: 83-89.

[16] COSSARI P, CANNAVAlE A, GAMBINO S, et al. Room temperature processing for solid-state electrochromic devices on single substrate: from glass to flexible plastic. Solar Energy Materials and Solar Cells, 2016, 155: 411-420.

[17] WANG Y A, MENG Z H, CHEN H, et al. Pulsed electrochemical deposition of porous $\mathrm{WO}_{3}$ on silver networks for highly flexible electrochromic devices. Journal of Materials Chemistry C, 2019, 7(7): 1966-1973

[18] XU Z J, LI W F, HUANG J N, et al. Controllable and large-scale fabrication of flexible ITO-free electrochromic devices by crackle pattern technology. Journal of Materials Chemistry A, 2018, 6(40): 19584-19589.

[19] LIU Y, LÜ Y, TANG Z B, et al. Highly stable and flexible ITOfree electrochromic films with bi-functional stacked $\mathrm{MoO}_{3} / \mathrm{Ag} / \mathrm{MoO}_{3}$ structures. Electrochimica Acta, 2016, 189: 184-189.

[20] ZHANG H J, JEON K W, SEO D K. Equipment-free deposition of graphene-based molybdenum oxide nanohybrid Langmuir Blodgett films for flexible electrochromic panel application. ACS Applied Materials \& Interfaces, 2016, 8(32): 21539-21544.

[21] BODUROV G, STEFCHEV P, IVANOVA T. Investigation of electrodeposited $\mathrm{NiO}$ films as electrochromic material for counter electrodes in smart windows. Mater. Lett., 2014, 117: 270-272.

[22] DONG D M, WANG W W, GUO B, et al. Electrochromic properties and performance of $\mathrm{NiO}_{x}$ films and their corresponding all-thin-film flexible devices prepared by reactive DC magnetron sputtering. Applied Surface Science, 2016, 383: 49-56. 
[23] BI Z J, LI X M, CHEN Y B, et al. Bi-functional flexible electrodes based on tungsten trioxide/zinc oxide nanocomposites for electrochromic and energy storage applications. Electrochimica Acta, 2017, 227: 61-68.

[24] HEO S, KIM J, ONG G K, et al. Template-free mesoporous electrochromic films on flexible substrates from tungsten oxide nanorods. Nano Letters, 2017, 17(9): 5756-5761.

[25] LEE S J, LEE T G, NAHM S, et al. Investigation of all-solid-state electrochromic devices with durability enhanced tungsten-doped nickel oxide as a counter electrode. Journal of Alloys and Compounds, 2020, 815: 152399.

[26] LI H, VIENNEAU G, JONES M, et al. Crack-free 2D-inverse opal anatase $\mathrm{TiO}_{2}$ films on rigid and flexible transparent conducting substrates: low temperature large area fabrication and electrochromic properties. Journal of Materials Chemistry C, 2014, 2(37): 7804-7810.

[27] WU J, QIU D, ZHANG H L, et al. Flexible electrochromic $\mathrm{V}_{2} \mathrm{O}_{5}$ thin films with ultrahigh coloration efficiency on graphene electrodes. Journal of the Electrochemical Society, 2018, 165(5): 183-189.

[28] WANG J Y, WANG M C, JAN D J. Synthesis of poly(methyl methacrylate)-succinonitrile composite polymer electrolyte and its application for flexible electrochromic devices. Solar Energy Materials and Solar Cells, 2017, 160: 476-483.

[29] ZHANG X W, JING Y, ZHAI Q F, et al. Point-of-care diagnoses: flexible patterning technique for self-powered wearable sensors. Analytical Chemistry, 2018, 90(20): 11780-11784.

[30] QIU M J, SUN P, LIU Y J, et al. Visualized UV photodetectors based on prussian blue/ $\mathrm{TiO}_{2}$ for smart irradiation monitoring application. Advanced Materials Technologies, 2018, 3(2): 1700288.

[31] MACHER S, SCHOTT M, SASSI M, et al. New roll-to-roll processable PEDOT-based polymer with colorless bleached state for flexible electrochromic devices. Advanced Functional Materials, 2020, 30(6): 1906254.

[32] DIAZ-SANCHEZ J, ROSAS-ABURTO A, VIVALDO-LIMA E, et al. Development and characterization of a flexible electrochromic device based on polyaniline and enzymatically synthesized poly (gallic acid). Synthetic Metals, 2017, 223: 43-48.

[33] AN T C, LING Y Z, GONG S, et al. A wearable second skin-like multifunctional supercapacitor with vertical gold nanowires and electrochromic polyaniline. Advanced Materials Technologies, 2019, 4: 1800473 .

[34] CHE B Y, ZHOU D, LI H, et al. A highly bendable transparent electrode for organic electrochromic devices. Organic Electronics, 2019, 66: 86-93.

[35] ZHOU K L, WANG H, JIU J T, et al. Polyaniline films with modified nanostructure for bifunctional flexible multicolor electro- chromic and supercapacitor applications. Chemical Engineering Journal, 2018, 345: 290-299.

[36] ZHANG S H, CHEN S, HU F, et al. Patterned flexible electrochromic device based on monodisperse silica/polyaniline core/shell nanospheres. Journal of the Electrochemical Society, 2019, 166(8): H343-H350.

[37] LI X B, ZHANG L P, WANG B, et al. Highly-conductive porous poly(ether ether ketone) electrolyte membranes for flexible electrochromic devices with variable infrared emittance. Electrochimica Acta, 2020, 332: 135357.

[38] DENG B, HSU P C, CHEN G C, et al. Roll-to-roll encapsulation of metal nanowires between graphene and plastic substrate for high-performance flexible transparent electrodes. Nano Letters, 2015, 15(6): 4206-4213.

[39] SINGH R, THARION J, MURUGAN S, et al. ITO-free solutionprocessed flexible electrochromic devices based on PEDOT: PSS as transparent conducting electrode. ACS Applied Materials \& Interfaces, 2017, 9(23): 19427-19435.

[40] KIM K W, LEE S B, KIM S H, et al. Spray-coated transparent hybrid electrodes for high-performance electrochromic devices on plastic. Organic Electronics, 2018, 62: 151-156.

[41] SANGLEE K, CHUANGCHOTE S, CHAIWIWATWORAKUL P, et al. PEDOT: PSS nanofilms fabricated by a nonconventional coating method for uses as transparent conducting electrodes in flexible electrochromic devices. Journal of Nanomaterials, 2017(4): 5176481-1-8.

[42] OH H, SEO D G, YUN T Y, et al. Voltage-tunable multicolor, sub-1.5 V, flexible electrochromic devices based on ion gels. ACS Applied Materials \& Interfaces, 2017, 9(8): 7658-7665.

[43] SEO D G, MOON H C. Mechanically robust, highly ionic conductive gels based on random copolymers for bending durable electrochemical devices. Advanced Functional Materials, 2018, 28(14): 1706948

[44] KIM J W, MYOUNG J M. Flexible and transparent electrochromic displays with simultaneously implementable subpixelated ion gel-based viologens by multiple patterning. Advanced Functional Materials, 2019, 29(13): 1808911.

[45] VINUALES A, ALESANCO Y, CABANERO G, et al. Incorporating paper matrix into flexible devices based on liquid electrochromic mixtures: enhanced robustness, durability and multicolor versatility. Solar Energy Materials and Solar Cells, 2017, 167: $22-27$.

[46] MOON H C, LODGE T P, FRISBIE C D. Solution processable, electrochromic ion gels for sub-1 V, flexible displays on plastic. Chemistry of Materials, 2015, 27(4): 1420-1425.

[47] ZHANG B, LI X, GONG G, et al. Preparation and stability of flexible electrochromic devices based on metal supramolecular 
polymers. Journal of Beijing Institute of Clothing Technology, 2018, 38(4): 13-20.

[48] CHEN B H, KAO S Y, HU C W, et al. Printed multicolor high-contrast electrochromic devices. ACS Applied Materials \& Interfaces, 2015, 7: 25069-25076.

[49] NUNES M, ARAUJO M, FONSECA J, et al. High performance electrochromic devices based on poly[Ni(salen)]-type polymer films. ACS Applied Materials \& Interfaces, 2016, 8(22): 14231-14243.

[50] LI K R, ZHANG Q H, WANG H Z, et al. Light weight, highly bendable and foldable electrochromic films based on all-solutionprocessed bilayer nanowire networks. Journal of Materials Chemistry C, 2016, 4(24): 5849-5857.

[51] LI G Q, GAO L X, LI L D, et al. An electrochromic and selfhealing multi-functional supercapacitor based on $\mathrm{PANI} / \mathrm{nw}-\mathrm{WO}_{2.7} /$ $\mathrm{Au}$ NPs electrode and hydrogel electrolyte. Journal of Alloys and Compounds, 2019, 786: 40-49.

[52] CAI G F, DARMAWAN P, CUI M Q, et al. Highly stable transparent conductive silver grid/PEDOT: PSS electrodes for integrated bifunctional flexible electrochromic supercapacitors. Advanced Energy Materials, 2015, 6(4): 1501882.

[53] QU H Y, ZHANG X, ZHANG H C, et al. Highly robust and flexible $\mathrm{WO}_{3} \cdot 2 \mathrm{H}_{2} \mathrm{O} / \mathrm{PEDOT}$ films for improved electrochromic performance in near-infrared region. Solar Energy Materials and Solar Cells, 2017, 163: 23-30.

[54] ALESANCO Y, PALENZUELA J, TENA-ZAERA R, et al. Plastic electrochromic devices based on viologen-modified $\mathrm{TiO}_{2}$ films prepared at low temperature. Solar Energy Materials and Solar Cells, 2016, 157: 624-635.

[55] GINTING R T, OVHAL M M, KANG J W. A novel design of hybrid transparent electrodes for high performance and ultra-flexible bifunctional electrochromic-supercapacitors. Nano Energy, 2018, 53: 650-657.

[56] WADE C R, Li M, DINCA M. Facile deposition of multicolored electrochromic metal-organic framework thin films. Angew. Chem. Int. Ed., 2013, 52: 13377-13381.

[57] MJEJRI I, DOHERTY C M, RUBIO-MARTINEZ M, et al. Double-sided electrochromic device based on metal-organic frameworks. ACS Appl. Mater. Interfaces, 2017, 9(46): 39930-39934.

[58] JIANG Q, CHEN M, LI J, et al. Electrochemical doping of halide perovskites with ion intercalation. ACS Nano, 2017, 11: 1073-1079.
[59] SALLES P, PINTO D, HANTANASIRISAKUL K, et al. Electrochromic effect in titanium carbide MXene thin films produced by dip-coating. Adv. Funct. Mater., 2019, 29: 1809223.

[60] CHAUDHARI A K, SOUZA B E, TAN J C. Electrochromic thin films of Zn-based MOF-74 nanocrystals facilely grown on flexible conducting substrates at room temperature. APL Materials, 2019, 7(8): 081101.

[61] LIU Q, XU Z J, QIU W, et al. Ultraflexible, stretchable and fastswitching electrochromic devices with enhanced cycling stability. RSC Advances, 2018, 8: 18690-18697.

[62] CHEN W H, LI F W, LIOU G S. Novel stretchable ambipolar electrochromic devices based on highly transparent AgNW/PDMS hybrid electrodes. Advanced Optical Materials, 2019, 7(19): 1900632.

[63] LIU H S, PAN B C, LIOU G S. Highly transparent AgNW/PDMS stretchable electrodes for elastomeric electrochromic devices. Nanoscale, 2017, 9(7): 2633-2639.

[64] VARGHESE HANSEN R, YANG J L, ZHENG L X. Flexible electrochromic materials based on CNT/PDA hybrids. Advances in Colloid and Interface Science, 2018, 258: 21-35.

[65] YUN T G, PARK M, KIM D H, et al. All-transparent stretchable electrochromic supercapacitor wearable patch device. ACS Nano, 2019, 13(3): 3141-3150.

[66] CAI G F, PARK S, CHENG X, et al. Inkjet-printed metal oxide nanoparticles on elastomer for strain-adaptive transmissive electrochromic energy storage systems. Science And Technology of Advanced Materials, 2018, 19(1): 759-770.

[67] KIM D S, PARK H, HONG S Y, et al. Low power stretchable active-matrix red, green, blue (RGB) electrochromic device array of poly(3-methylthiophene)/Prussian blue. Applied Surface Science, 2019, 471: 300-308

[68] ZHAO P F, CHEN H L, LI B, et al. Stretchable electrochromic devices enabled via shape memory alloy composites (SMAC) for dynamic camouflage. Optical Materials, 2019, 94: 378-386.

[69] ZHENG R Z, WANG Y, JIA C Y, et al. Intelligent biomimetic chameleon skin with excellent self-healing and electrochromic properties. ACS Applied Materials \& Interfaces, 2018, 10(41): 35533-35538.

[70] WU Q, ZHANG G G, CHEN H X, et al. The state-of-the-art flexible electrochromic material. Journal of Functional Materials, 2019, 50(10): 10040-10046. 